\title{
The relation between non-occupational physical activity and years lived with and without disability
}

W J Nusselder, C W N Looman, O H Franco, A Peeters, A S Slingerland and J P Mackenbach

J. Epidemiol. Community Health 2008;62;823-828

doi:10.1136/jech.2007.067165

Updated information and services can be found at:

http://jech.bmj.com/cgi/content/full/62/9/823

These include:

References This article cites 40 articles, 18 of which can be accessed free at: http://jech.bmj.com/cgi/content/full/62/9/823\#BIBL

Rapid responses You can respond to this article at:

http://jech.bmj.com/cgi/eletter-submit/62/9/823

Email alerting Receive free email alerts when new articles cite this article - sign up in the box at service the top right corner of the article

Notes

To order reprints of this article go to:

http://journals.bmj.com/cgi/reprintform

To subscribe to Journal of Epidemiology and Community Health go to:

http://journals.bmj.com/subscriptions/ 


\title{
The relation between non-occupational physical activity and years lived with and without disability
}

\author{
W J Nusselder, ${ }^{1}$ C W N Looman, ${ }^{1}$ O H Franco, ${ }^{2}$ A Peeters, ${ }^{3}$ A S Slingerland, ${ }^{1}$ \\ J P Mackenbach ${ }^{1}$
}

${ }^{1}$ Department of Public Health, Erasmus MC, University Medical Center Rotterdam, Rotterdam, The Netherlands; ${ }^{2}$ Unilever Corporate Research, Colworth House, Sharnbrook, UK; Erasmus MC. University Medical Center Rotterdam, Department of Public Health, Rotterdam, The Netherlands; ${ }^{3}$ Department of Epidemiology and Preventive Medicine, Monash University Central and Eastern Clinical School, Melbourne, Australia

Correspondence to:

Dr W J Nusselder, Department of Public Health, Erasmus University Medical Center, Rotterdam, PO Box 2040, 3000 CA Rotterdam, the Netherlands; w.nusselder@erasmusmc.nl

Accepted 17 December 2007

\section{ABSTRACT}

Objectives: The effects of non-occupational physical activity were assessed on the number of years lived with and without disability between age 50 and 80 years.

Methods: Using the GLOBE study and the Longitudinal Study of Aging, multi-state life tables were constructed yielding the number of years with and without disability between age 50 and 80 years. To obtain life tables by level of physical activity (low, moderate, high), hazard ratios were derived for different physical activity levels per transition (non-disabled to disabled, non-disabled to death, disabled to non-disabled, disabled to death) adjusted for age, sex and confounders.

Results: Moderate, compared to low non-occupational physical activity reduced incidence of disability (HR 0.66 , $95 \% \mathrm{Cl} 0.51$ to 0.86 ), increased recovery (HR 1.95, 95\% Cl 1.32 to 2.87), and represents a gain of disability-free years and a loss of years with disability (male 3.1 and 1.2; female 4.0 and 2.8 years). Performing high levels of nonoccupational physical activity further reduced incidence, and showed a higher gain in disability-free years (male 4.1; female 4.7), but a similar reduction in years with disability.

Conclusion: Among 50-80-year-olds promoting physical activity is a fundamental factor to achieve healthy ageing.

In 20251.2 billion people worldwide will be aged 60 years and over. ${ }^{1}$ Living longer is a societal achievement, but also a source of concern as prevalence of major chronic diseases and disability increase with age. A rising share of older age groups in the population will increase the burden of morbidity and will put an upward pressure on costs. The number of older people with severe disability may be $40 \%$ to $75 \%$ higher by 2030 because of population ageing. ${ }^{2}$ Health and longterm care spending is projected to almost double by 2050 across members of the Organization of Economic Cooperation and Development (OECD). In the approach of "healthy" ageing, however, these consequences might be mitigated.

Physical activity is an important candidate tool to achieve healthy ageing. Physical activity reduces mortality, ${ }^{3}$ extends life expectancy ${ }^{4}$ and delays the onset of chronic diseases, including cardiovascular disease (CVD), cancer and diabetes. ${ }^{3-5}$ Increasing evidence exists that physical activity also delays the onset of disability, ${ }^{6-22}$ and increases the chances $^{81522-24}$ and duration of recovery from disability. ${ }^{23}$

Although an active lifestyle has been found to increase life expectancy in some studies and to reduce disability in others, its overall effect on health is still largely unknown. There are limited data about the effects of physical activity on the number of years with and without disability and these effects are not easy to predict. The effects of risk factors for both disability and death, such as physical activity, can follow different directions. ${ }^{25}$ Therefore, it is unclear whether the extra years gained by engaging in a physically active lifestyle will be free of disability or will add to the time lived with disability.

The aim of this study is to assess the effects of non-occupational physical activity on life expectancy and the number of years lived with and without disability in 50-80-year-olds.

\section{METHODS}

Multi-state life tables (MSLTs) were constructed to calculate the number of years with and without disability. A MSLT consists of different states (in this study "non-disabled", "disabled" and "death") that persons can leave and (re)enter. ${ }^{26}$ Transition rates were estimated between these states, and the influence of physical activity on these transition rates was assessed by including information on their association (hazard ratios, HR) and the prevalence of physical activity.

\section{Survey design}

The primary dataset used was the GLOBE study. GLOBE is the Dutch acronym for Health and Living Conditions in the population of Eindhoven and Surroundings. ${ }^{27}$ A postal questionnaire was sent in 1991 to approximately 27000 Dutch nationals aged 15-74 years living in the city of Eindhoven and surrounding municipalities (response rate $70.3 \%$ ) This questionnaire was extended with an oral interview in two subsamples. The first was a random selection of 3529 people from respondents of the postal survey (response rate $79.3 \%, n=2800$ ). In the second subsample of 3970 respondents, people with diabetes mellitus, heart disease, chronic bronchitis, or chronic back complaints were oversampled (response rate $72.2 \%, \mathrm{n}=2867$ ). Both sub-samples were followed up in 1993, 1995 and 1997 allowing for 2-year observation intervals. To increase the power of the study, the sub-samples were pooled $(\mathrm{n}=5667)$. Follow-up information was available for 4496 subjects $(79.4 \%$, including deaths $81.1 \%$ ) in $1993,4105(72.4 \%, 76.4 \%)$ in 1995 and 4246 $(74.9 \%, 81.4 \%)$ in 1997 . Data on mortality were obtained from administrative follow-up in municipal population registers.

As the GLOBE study did not comprise persons above age 74 at baseline, the Longitudinal Study of 
Aging (LSOA) was used for the estimation of transition rates above age 74 . The LSOA started in 1984 and studied residents of the United States of America who were 70 years and over $(\mathrm{n}=7527) .{ }^{28}$ The complete sample was re-interviewed in 1988 ( $n=4984$, response $66.2 \%, 89.0 \%$ including deaths) and in 1990 ( $\mathrm{n}=4142,55.0 \%, 87.4 \%)$, and a sub-sample in $1986(\mathrm{n}=4113$, $79.8 \%, 92.4 \%$ ), also allowing for 2 -year observation intervals. Information on mortality was available from linkage with the National Death Index.

\section{Sample population}

Of the 5667 respondents of the GLOBE study, 5629 were present at the start of one of the 2-year observation intervals. From these, 3759 subjects were selected who were 50 years and over at the start of the interval. Complete information on disability and mortality at the start and end of the 2-year observation interval was available for 2966 subjects $(78.9 \%$; 6160 observation-intervals).

For the LSOA study, of the 7527 respondents, 6491 were present at the start of one of the 2-year observation intervals. There was no selection on age. Complete information on disability and mortality at the start and end of the 2-year observation interval was available for 5547 subjects $(85.9 \%$; 10904 observation intervals).

\section{Disability}

Disability was measured using the OECD questionnaire ${ }^{29}$ and a questionnaire with additional items on Activities of Daily Living (ADL) and mobility. ${ }^{30}$ Subjects were asked whether they were able to get in/out of bed, get in/out of a chair, bathe, dress, lift/ carry something, walk up/downstairs, get outside, and walk a quarter of a mile. Similar questions were also included in the LSOA questionnaire. Subjects were asked to assess their level of ability: "with no difficulty", "some difficulty", "a lot of difficulty", "needed help" or "were unable to". Respondents to one or more of the latter three categories were considered disabled.

\section{Physical activity}

Questions on physical activity in the 1991 postal survey of the GLOBE study were: (1) time spent daily on walking or biking to shops or work (minutes); (2) time spent weekly on walking, biking or gardening in leisure time ( $<30$ minutes, 30 minutes1 hour, 1-2 hours, $>2$ hours); and (3) time spent weekly on sports (<30 minutes, 30 minutes-1 hour, 1-2 hours, $>2$ hours). If a person reported they did sports, the main type of sport was assessed. Less than 30 minutes per week was regarded as 0, 30 minutes to 1 hour as 50 minutes, $1-2$ hours as 90 minutes, and $>2$ hours as 130 minutes. We calculated a summary measure by multiplying the number of hours (minutes/60) per week with the appropriate Metabolic Equivalent Task-hours (MET value) from the Compendium of physical activity. ${ }^{31}$ A MET score of 1 represents the energy spent sitting quietly and is equivalent to $3.5 \mathrm{~mL} \mathrm{O}_{2}$ per kilogram of body weight per hour. A MET score of 4 was used for walking or biking to the shops or work, and for walking, biking or gardening in leisure time. ${ }^{31}$ For sports, the MET score corresponding to the main sport was derived from the Compendium. ${ }^{31}$ The weekly summary measure of physical activity in the study sample ranged from 0 to $27.8(90 \%$ trimmed range). Based on tertiles, the population was classified into low $(<12)$, moderate $(12-17.33)$ and high $(>17.33)$ physical activity levels.

\section{Potential confounders}

All analyses were stratified by, or adjusted for age and sex. Based on the literature, ${ }^{32}$ the following variables were considered as potential confounders: education, smoking (never/ever/ current), marital status (single/married/widowed/divorced), self-reported diseases at baseline, and psychosocial factors (locus of control/coping/social support). Education was categorised as high (vocational schooling and university), 2 (intermediate vocational or intermediate/higher schooling), 3 (lower vocational or secondary schooling) and low (primary school only). Diseases at baseline comprised any of the following: cancer, CVD, COPD, back complaints, arthritis and neurological diseases. Detailed information on the measurement of these variables is given elsewhere. ${ }^{33}$ If the number of missing cases for a confounder exceeded 100, a category was added for missing values to avoid changes in the HRs due to selection of nonmissing observations.

Body Mass Index (BMI) was not considered a confounder but an intermediate variable $e^{34}$, as BMI may represent a step in the causal chain between physical activity, and disability or mortality.

\section{Data analyses}

\section{Overall transition rates}

Overall transition rates were estimated based on all 17064 (6160 GLOBE+10 904 LSOA) 2-year observation intervals for the transitions: non-disabled to disabled (incidence), disabled to non-disabled (recovery), non-disabled to death (non-disabled mortality), and disabled to death (disabled mortality). A previous study showed that the GLOBE and LSOA studies could be adequately pooled for the calculation of these transition rates, and that the frequency of disability and mortality in both studies closely represented the Dutch levels. ${ }^{35}$ Less than $4 \%(n=85)$ of the respondents experienced the same transition twice. Age-specific transition rates were estimated with Poisson regression using exponential curves to model the association of the transitions with age.

\section{Hazard ratios (HRs)}

To assess whether physical activity was associated with each of the transitions, data from the GLOBE study were used with Poisson regression. The effect of potential confounders (education, smoking, marital status, chronic disease at baseline, and psychosocial factors) was analysed by first adjusting for age and sex, and by adding those variables that substantially changed the HRs in the final model (education, chronic disease at baseline). To correct for reverse causation (i.e. lower physical activity levels might have been caused by ill health), the analyses were repeated after excluding the first 2 years' postmeasurement of physical activity.

\section{Transition rates by level of physical activity}

For each transition the transition rates were estimated by level of physical activity, using the (1) overall transition rates, (2) adjusted HRs (based on the final model and excluding the first 2 years' post-measurement of physical activity), and (3) prevalence of physical activity levels (based on the GLOBE population stratified by age, sex and disability status). ${ }^{35}$

\section{Partial life expectancies by level of physical activity}

To calculate the number of years lived with and without disability between age 50 and 80 (i.e. partial life expectancies), separate MSLTs were created for each sex and physical activity 
Table 1 Baseline characteristics of the GLOBE study population by levels of physical activity (low, moderate, high, missing)

\begin{tabular}{lllll}
\hline & \multicolumn{2}{l}{ Physical activity level: } & \\
\cline { 2 - 4 } & Low & Moderate & High & Missing \\
\hline N & 891 & 1239 & 744 & 92 \\
Age (mean (SD)) & $61.9(7.7)$ & $61.3(7.2)$ & $59.5(6.8)$ & $65.7(7.6)$ \\
Women (\%) & 47 & 46 & 53 & 70 \\
Education (\%) & & & & \\
$\quad 1$ High & 12 & 14 & 21 & 5 \\
2 & 16 & 16 & 22 & 4 \\
3 & 38 & 40 & 42 & 34 \\
4 Low & 32 & 28 & 14 & 38 \\
Missing* & 3 & 2 & 1 & 18 \\
Marital status (\%) & & & & \\
$\quad$ Married & 80 & 81 & 85 & 58 \\
$\quad$ Single & 5 & 5 & 3 & 9 \\
$\quad$ Divorced & 6 & 6 & 6 & 13 \\
$\quad$ Widowed & 8 & 7 & 6 & 12 \\
Smoking status (\%) & & & & \\
$\quad$ Never & 20 & 25 & 31 & 42 \\
$\quad$ Former & 39 & 41 & 46 & 32 \\
$\quad$ Current & 39 & 33 & 22 & 20 \\
Chronic disease $\dagger(\%))$ & & & & \\
$\quad$ No & 37 & 40 & 49 & 27 \\
$\quad$ Yes & 61 & 58 & 49 & 68 \\
$\quad$ Missing & 2 & 2 & 2 & 4 \\
Disability (\%) & 28 & 16 & 10 & 45 \\
BMI (mean (SD)) & $25.5(3.8)$ & $25.1(3.1)$ & $24.6(2.8)$ & $26.5(2.8)$ \\
\hline N N & & & \\
\hline
\end{tabular}

*Number of subjects with missing education exceeded 100 .

$\uparrow$ Any of the following self-reported diseases: cardiovascular disease, cancer, COPD, arthritis back complaints, neurological diseases.

Based on tertiles, the population was classified into low- $(<12)$, moderate- $(12-$ 17.33) and high-physical-activity (>17.33) levels.

category. These MSLTs started at age 50 with a population initially free of disability.

To explore whether the outcomes apply to the elderly population (including those aged 80 and over), the range of effects of physical activity on life expectancy with(out) disability at age 50 were assessed. The HRs for ages 80 and over were assumed to range between those for the age range 5080 and 1 (no protective effect).

Poisson regression was performed in GLIM (Generalized Linear Interactive Modelling 4 NAG Ltd., Oxford, UK). Normalised weights (with a mean of one) were used to take into account the complex sampling design and non-response (specifically, the overrepresentation of persons with chronic diseases in the GLOBE study and the difference in completeness of information on disability and mortality in both GLOBE and LSOA). Excel was used for the MSLT analyses and Monte Carlo simulation (parametric bootstrapping) ${ }^{36}$ in @RISK (Anonymous 2000; MathSoft Inc 1999) to calculate confidence intervals for the number of years with(out) disability and differences herein (10 000 runs).

\section{RESULTS}

\section{Baseline characteristics}

Respondents in the high-physical-activity group were significantly more likely to have received higher education and be married, and were less likely to be smokers, to have a chronic disease and to have disability, and had an almost $1 \mathrm{~kg} / \mathrm{m}^{2}$ lower BMI as compared with respondents in the low-activity group (table 1).

\section{Hazard ratios for level of physical activity}

Moderate physical activity levels, as compared with low levels, were associated with lower chances of incidence and mortality in those who were non-disabled, and with lower chances of mortality and higher chances of recovery once disabled (table 2).

These findings were more pronounced for the highest level of physical activity, although chances of recovery in this group were lower compared with moderate levels. A similar pattern of results was seen in the analyses adjusted solely for age and sex, adjusted for all relevant variables, and excluding the first 2 years' post-measurement of physical activity (table 2).

\section{Numbers of years lived with and without disability}

Taking all physical activity levels together, men are expected to live 25.0 years (22.7 without and 2.3 with disability) and women 27.4 years (22.4 without and 5.0 with disability) (data not shown). Those with a moderate physical activity level can expect to live significantly more years free of disability and fewer years with disability, compared with those with low activity levels (table 3). Respondents with high activity levels gained even more years free of disability than those with a moderate level, but showed no further reduction in years living with disability. Although for women, gains in partial life expectancy associated with physical activity were smaller than for men, more years were free of disability (figure 1). Explorative analyses including the oldest old showed that at least moderate activity as compared with low, increased life expectancy free of disability at age 50, but not life expectancy with disability (data available on request).

\section{DISCUSSION}

Moderate non-occupational physical activity lowers the rates of incidence of disability and death and increases the rates of recovery from disability in 50-80-year-olds. The overall effect on health being that moderate physical activity contributes to healthy ageing (i.e. extending disability-free years by 3 (men) to 4 (women) years) and fewer years with disability. Compared with moderate levels, higher levels of physical activity increased the number of years free of disability by $25 \%$, but did not change the number of years lived with disability any further.

Recovery from disability was not further enhanced by higher compared with moderate levels of physical activity. This could be attributed to either (1) moderate levels of physical activity being sufficient and attaining the highest possible degree of recovery, (2) higher levels of physical activity provoking other disability, levelling out any gains attained on the initial disability, or (3) that among the disabled those with high levels of physical activity were following a rehabilitation programme and, hence, were subject to "inverse" misclassification. ${ }^{12}$

To our knowledge, this study is one of the first to prospectively study the impact of physical activity on the number of disabled and non-disabled years. Most previous studies evaluated physical activity in combination with other risk factors, ${ }^{87-39}$ or, if only physical activity was studied, there was no correction for potential confounding. ${ }^{38}$ Moreover, prior studies focused on either life expectancy or on a single health state transition. ${ }^{671222} 244041$ This limits a clear overview as the diverse studies are hard to combine due to differences in the study population, length of follow-up, confounders included, measurement and classification of physical activity and disability. The perspective presented in this study covering all four potential transitions (incidence, recovery, non-disabled and disabled mortality) does provide such an overview. 
Table 2 Hazard ratios $(95 \% \mathrm{Cl})$ for the transitions non-disabled to disabled (incidence), disabled to non-disabled (recovery), non-disabled to death (non-disabled mortality), and disabled to death (disabled mortality) by level of physical activity (low, moderate, high) from the GLOBE study

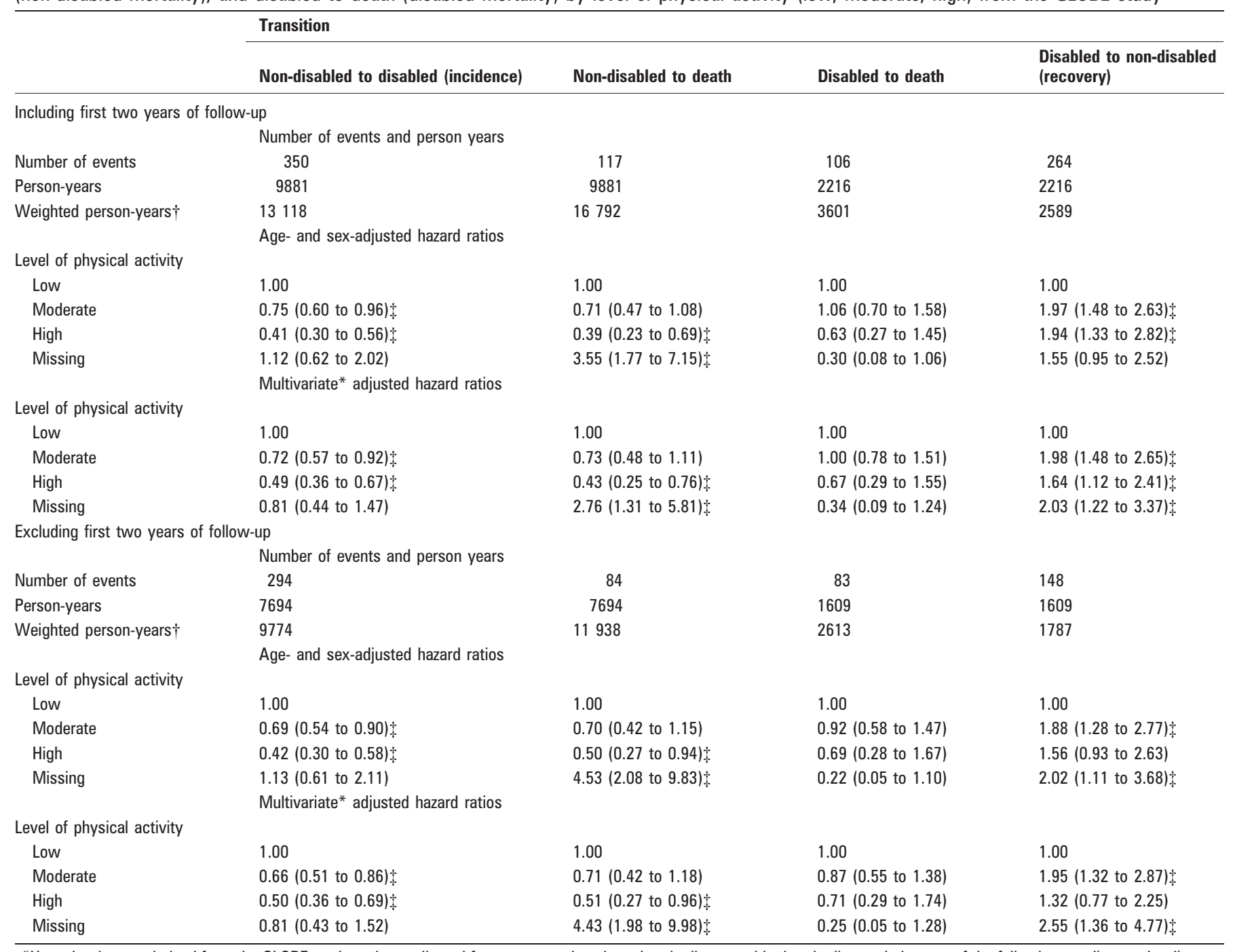

*Hazard ratios are derived from the GLOBE study and are adjusted for age, sex, education, chronic disease with chronic disease being any of the following: cardiovascular disease, cancer, COPD, arthritis back complaints, neurological diseases.

†Normalised weights (with a mean of one) were to take into account the complex sampling design and non-response.

\$HRs are significant at the 0.05 level.

Certain limitations should be acknowledged. These data are observational and, therefore, randomised trials are required to determine causality between physical activity and longer disability-free lives. Bias might have occurred by confounding or reverse causation. In this study, it was possible to adjust for the most obvious confounders between physical activity and disability (education, marital status, smoking, chronic disease, psychosocial factors) and to exclude the first 2 years' postmeasurement of physical activity. While correcting for baseline chronic diseases reduces reverse causation, if chronic diseases are in the causal pathway from physical inactivity to disability or death, it results in an underestimation of the effects of physical activity. However, correction for chronic diseases did not modify the present results. Another potential limitation was the measurement and classification of physical activity. Physical activity was based on self-reported information on the duration and type of physical activity. Hence, if respondents gave socially desirable answers, the effects would be less pronounced compared with other measures of physical activity. ${ }^{3}$ There is no reason to expect that physical activity levels are rated differently by disabled versus non-disabled people resulting in differential misclassification, apart from disabled people overestimating their physical activity because of the greater effort experienced. ${ }^{40}$ To classify persons into low, moderate and high physical activity levels, values were assigned to each time interval and METS scores to each group of activities. Assigning $0,40,75$, and 125 minutes, respectively, for the time intervals ( $<30$ minutes, 30 minutes-1 hour, 1-2 hours, $>2$ hours) and a MET score of 3.5 for walking/biking to work and the shops and walking, biking, gardening, would not change the tertile classification substantially (change of only $2.7 \%$ of the cases). Pooling the GLOBE and LSOA studies may also have introduced bias. However, as the LSOA study was used only to obtain transition rates, and prior analyses have shown that both studies together provide valid transition rates for the Netherlands, ${ }^{35}$ it is not expected to modify our conclusions. A final limitation is that the analysis is based in some cases on non-significant HRs. However, if these were all set to 1 (i.e. ignoring non-significant effects) the major conclusions did not change (data available on request).

The present findings are in line with studies showing physical activity to reduce mortality ${ }^{3}$ and increase life expectancy. ${ }^{4}$ The 
Table 3 Partial life expectancy at age 50 (in years), total, free of disability and with disability (mean (95\%CI)) according to level of physical activity (PA), stratified by sex, from the GLOBE and LSOA study

\begin{tabular}{|c|c|c|c|c|c|c|}
\hline & \multicolumn{6}{|l|}{ Number of years } \\
\hline & \multicolumn{2}{|c|}{ Partial life expectancy } & \multicolumn{2}{|c|}{ Years free of disability } & \multicolumn{2}{|c|}{ Years with disability } \\
\hline & Absolute number & $\begin{array}{l}\text { Difference compared to low } \\
\text { level of PA }\end{array}$ & Absolute number & $\begin{array}{l}\text { Difference compared to } \\
\text { low level of PA }\end{array}$ & Absolute number & $\begin{array}{l}\text { Difference compared to } \\
\text { low level of PA }\end{array}$ \\
\hline \multicolumn{7}{|l|}{ Males } \\
\hline \multicolumn{7}{|c|}{ Level of physical activity } \\
\hline Low & 23.8 (22.8 to 24.8 ) & Ref & 20.7 (19.6 to 21.8$)$ & Ref & 3.1 (2.6 to 3.7$)$ & Ref \\
\hline \multicolumn{7}{|l|}{ Females } \\
\hline \multicolumn{7}{|c|}{ Level of physical activity } \\
\hline Low & 26.5 (25.8 to 27.2 ) & Ref & $19.3(18.1$ to 20.5$)$ & Ref & 7.2 (6.2 to 8.2 ) & Ref \\
\hline Moderate & 27.7 (27.0 to 28.3 ) & $1.3(0.3$ to 2.1$) \neq$ & 23.3 (22.1 to 24.4$)$ & $4.0(2.3$ to 5.6$) \neq$ & 4.4 (3.5 to 5.4$)$ & $-2.8(-4.1$ to -1.4$) t$ \\
\hline High & $28.3(27.2$ to 29.0$)$ & $1.8(0.5$ to 2.7$) \neq$ & 24.0 (22.3 to 25.5$)$ & $4.7(2.6$ to 6.5$)$ : & $4.3(3.0$ to 5.7$)$ & $-2.9(-4.5$ to -1.2$) \div$ \\
\hline
\end{tabular}

results agree with a randomised clinical trial showing physical activity to reduce the incidence of disability ${ }^{7}$ and other studies that merely focused on this transition. ${ }^{6-22}$ Finally, the results are in line with prior studies showing that among those with disability, physical activity reduces mortality ${ }^{40}$ and increases recovery. ${ }^{1524} 42$

There are many possible explanations why physical activity would not only prolong life but also reduce the years with disability. Evidence of causal associations and biological plausibility exists for diabetes, CVD, and obesity, and to some extent for osteoporosis and low back pain, ${ }^{43}$ which are risk factors of disability. ${ }^{64}$ Physical activity helps to maintain basic abilities that oppose disability such as improving strength, flexibility and aerobic capacity. ${ }^{45}{ }^{46}$ Furthermore, it prevents psychosocial dysfunction which also generates disability. ${ }^{47-49}$

The present results emphasise the importance of following and promoting a physically active lifestyle among the ageing population. The higher number of years of life lived without disability combined with the fewer years lived with disability in those with higher physical activity levels, suggests that ageing will not necessarily result in a medical and socio-economical burden.

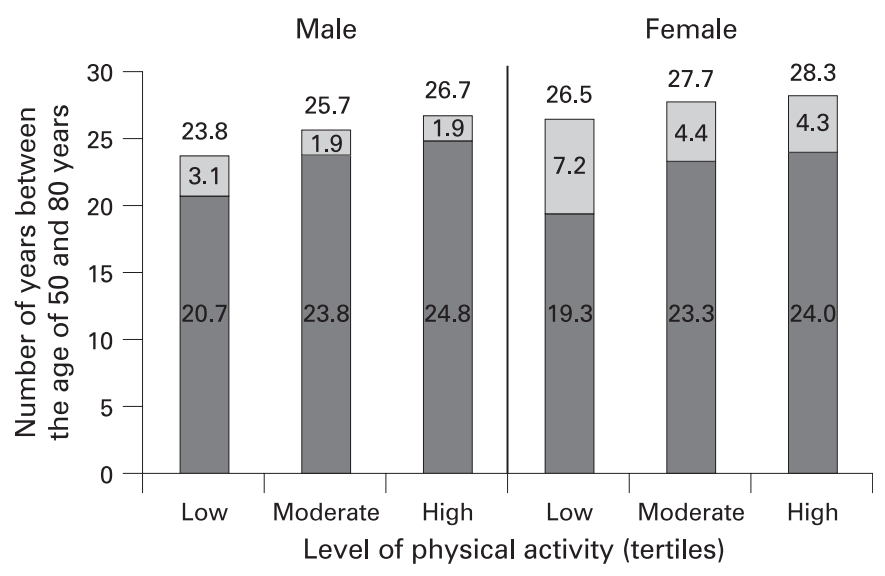

Figure 1 Partial life expectancy, years without and years with disability according to level of physical activity. Total number of years between the age of 50 and 80 (partial life expectancy), years without and years with disability according to level of physical activity. Data are shown for males and females separately. Years without disability are shown in solid grey columns. Years with disability in light grey columns on top of the columns representing the years without disability.
Instead, living longer and living more healthily may go hand in hand. Safely raising the levels of physical activity among the elderly will be a crucial step towards achieving healthy ageing.

\section{What is already known on this subject}

Physical activity reduces the risks of mortality, chronic diseases and disability.

- It is unknown whether the increased life expectancy is due to an increased number of years with disability and/or disabilityfree years.

\section{What this study adds}

Among 50-80-year-olds, physical activity extends the number of disability-free years and reduces the number of years with disability.

- Hence, physical activity may reduce the suggested medical and socio-economical burden associated with ageing.

\section{Policy implication}

Safely raising the levels of physical activity among the elderly will be a crucial step towards achieving healthy ageing and should be actively advocated.

Acknowledgements: The authors wish to thank Jan Barendregt for his assistance in using@RISK to produce confidence intervals.

Funding: This study was supported by a grant from the Netherlands Organization for Scientific Research (ZON-MW grant: 014-91-054). WN, CL, AP and OHF were partly funded by the Netherlands Organization for Scientific Research (ZON-MW grants: 01491-054). AP was also partly funded as a VicHealth Public Health Research Fellow. The funding organizations did not participate in and did not influence the design and conduct of the study, collection, management, analysis or interpretation of the data; preparation, reviewing or approval of the manuscript.

Competing interests: None. 


\section{REFERENCES}

1. World Health Organization. Aging and the life course. WHO, 13 October 2007. http://www.who.int/ageing/en/

2. Lafortune G, Balestat G, the Disability Study Expert Group Members. Trends in Severe Disability Among Elderly People: Assessing the Evidence in 12 OECD Countries and the Future Implications. Paris, France: OECD, 2007.

3. US Department of Health and Human Services, Centers for Disease Control and Prevention National Center for Chronic Disease Prevention and Health Promotion. Physical Activity and Health: A Report of the Surgeon General. Atlanta, GA: Department of Health and Human Services, Centers for Disease Control and Prevention, National Centre for Chronic Disease Prevention and Health Promotion, 1996.

4. Franco $\mathbf{O H}$, de Laet $\mathrm{C}$, Peeters $\mathrm{A}$, et al. Effects of physical activity on life expectancy with cardiovascular disease. Arch Intern Med 2005;165:2355-60.

5. Jonker JT, De Laet C, Franco $\mathrm{OH}$, et al. Physical activity and life expectancy with and without diabetes: life table analysis of the Framingham Heart Study. Diabetes Care 2006;29:38-43.

6. Stuck AE, Walthert JM, Nikolaus T, et al. Risk factors for functional status decline in community-living elderly people: a systematic literature review. Soc Sci Med 1999;48:445-69.

7. Penninx BW, Messier SP, Rejeski WJ, et al. Physical exercise and the prevention of disability in activities of daily living in older persons with osteoarthritis. Arch Intern Med 2001;161:2309-16.

8. Ferrucci L, Izmirlian G, Leveille $\mathrm{S}$, et al. Smoking, physical activity, and active life expectancy. Am J Epidemiol 1999;149:645-53.

9. Gregory PC, Gallo JJ, Armenian H. occupational physical activity and the development of impaired mobility: the 12-year follow-up of the Baltimore Epidemiologic Catchment Area sample. Am J Phys Med Rehabil 2001;80:270-5.

10. Van Den Brink CL, Picavet H, Van Den Bos GA, et al. Duration and intensity of physical activity and disability among European elderly men. Disabil Rehabil 2005;27:341-7.

11. LaCroix AZ, Guralnik JM, Berkman LF, et al. Maintaining mobility in late life. II. Smoking, alcohol consumption, physical activity, and body mass index. Am J Epidemiol 1993;137:858-69.

12. Simonsick EM, Lafferty ME, Phillips CL, et al. Risk due to inactivity in physically capable older adults. Am J Public Health 1993;83:1443-50.

13. Wu SC, Leu SY, Li CY. Incidence of and predictors for chronic disability in activities of daily living among older people in Taiwan. J Am Geriatr Soc 1999;47:1082-6.

14. He XZ, Baker DW. Body mass index, physical activity, and the risk of decline in overall health and physical functioning in late middle age. Am J Public Health 2004;94:1567-73.

15. Haight T, Tager I, Sternfeld B, et al. Effects of body composition and leisure-time physical activity on transitions in physical functioning in the elderly. Am J Epidemiol 2005; 162:607-17.

16. Branch LG. Health practices and incident disability among the elderly. Am J Public Health 1985;75:1436-9

17. Mor V, Murphy J, Masterson-Allen S, et al. Risk of functional decline among well elders. J Clin Epidemiol 1989;42:895-904.

18. Cassou B, Derriennic F, Monfort C, et al. [Predictive factors of physical disability in a cohort of retired persons in Paris followed during 10 years] Facteurs predictifs d'incapacite physique dans une cohorte de retraites parisiens suivis pendant dix ans. Rev Epidemiol Sante Publique 1997;45:382-91.

19. Avlund K, Damsgaard MT, Sakari-Rantala R, et al. Tiredness in daily activities among nondisabled old people as determinant of onset of disability. J Clin Epidemiol 2002; 55:965-73.

20. Reynolds SL, Silverstein M. Observing the onset of disability in older adults. Soc Sci Med 2003:57:1875-89.

21. Ho SC, Woo J, Yuen YK, et al. Predictors of mobility decline: the Hong Kong old-old study. J Gerontol A Biol Sci Med Sci 1997;52:M356-62.

22. Miller ME, Rejeski WJ, Reboussin BA, et al. Physical activity, functional limitations, and disability in older adults. J Am Geriatr Soc 2000;48:1264-72.

23. Hardy SE, Gill TM. Factors associated with recovery of independence among newly disabled older persons. Arch Intern Med 2005;165:106-12.
24. Gill TM, Robison JT, Tinetti ME. Predictors of recovery in activities of daily living among disabled older persons living in the community. J Gen Intern Med 1997:12:757-62.

25. Nusselder WJ, Peeters A. Successful aging: measuring the years lived with functional loss. J Epidemiol Community Health 2006;60:448-55.

26. Schoen R. Modelling multigroup populations. New York, NY: Plenum Press, 1988.

27. Mackenbach JP, van de Mheen H, Stronks K. A prospective cohort study investigating the explanation of socio-economic inequalities in health in The Netherlands. Soc Sci Med 1994;38:299-308.

28. Kovar MG, Fitty JE, Chyba MM. The Longitudinal Study of Aging: 1984-1990. Vital and Health Statistics [DHHS Publication PHS 92-1304] 1992;1.

29. McWhinnie JR. Disability assessment in population surveys: results of the 0.E.C.D. Common Development Effort. Rev Epidemiol Sante Publique 1981;29:413-9.

30. Statistics Netherlands. Netherlands Health Interview Survey, 1981-1991. The Hague: SDU, 1992.

31. Ainsworth BE, Haskell WL, Whitt MC, et al. Compendium of physical activities: an update of activity codes and MET intensities. Med Sci Sports Exerc 2000; 32: $5498-504$.

32. Stuck AE, Walthert JM, Nikolaus T, et al. Risk factors for functional status decline in community-living elderly people: a systematic literature review. Soc Sci Med 1999;48:445-69.

33. Nusselder WJ, Looman CW, Mackenbach JP. Nondisease factors affected trajectories of disability in a prospective study. J Clin Epidemiol 2005;58:484-94.

34. Rothman K GS. Modern Epidemiology. Philadelphia: Lippincott-Raven, 1998.

35. Nusselder WJ, Looman CW, Marang-van de Mheen PJ, et al. Smoking and the compression of morbidity. J Epidemiol Community Health 2000;54:566-74.

36. Efron B. TR. An Introduction to the Bootstrap. New York, NY: Chapman and Hall, 1993.

37. Vita AJ, Terry RB, Hubert HB, et al. Aging, health risks, and cumulative disability. N Engl J Med 1998;338:1035-41.

38. Belanger A, Martel L, Berthelot JM, et al. Gender differences in disability-free life expectancy for selected risk factors and chronic conditions in Canada. J Women Aging 2002;14:61-83.

39. Hubert HB, Bloch DA, Oehlert JW, et al. Lifestyle habits and compression of morbidity. J Gerontol A Biol Sci Med Sci 2002;57:M347-51.

40. Hirvensalo M, Rantanen T, Heikkinen E. Mobility difficulties and physical activity as predictors of mortality and loss of independence in the community-living older population. J Am Geriatr Soc 2000;48:493-8.

41. Rakowski W, Mor V. The association of physical activity with mortality among older adults in the Longitudinal Study of Aging (1984-1988). J Gerontol 1992;47:M122-9.

42. Hardy SE, Gill TM. Recovery from disability among community-dwelling older persons. Jama 2004;291:1596-602.

43. Bull F, Armstrong T, Dixon T, et al. Physical Activity. In: Ezzati M, Lopez AD, Rodgers A, Murray CJL, eds. Comparative Quantification of Health Risks Global and Regional Burden of Diseases Attributable to Selected Major Risk Factors. Geneva, Switzerland: WHO, 2004.

44. Hughes VA, Frontera WR, Roubenoff R, et al. Longitudinal changes in body composition in older men and women: role of body weight change and physical activity. Am J Clin Nutr 2002;76:473-81.

45. Keysor JJ. Does late-life physical activity or exercise prevent or minimize disablement? A critical review of the scientific evidence. Am J Prev Med 2003:25:129-36.

46. Buchner DM. Physical activity to prevent or reverse disability in sedentary older adults. Am J Prev Med 2003;25:214-5.

47. Seeman $\mathbf{T}$, Chen X. Risk and protective factors for physical functioning in older adults with and without chronic conditions: MacArthur Studies of Successful Aging. J Gerontol B Psychol Sci Soc Sci 2002;57:S135-44.

48. Netz Y, Wu MJ, Becker BJ, et al. Physical activity and psychological well-being in advanced age: a meta-analysis of intervention studies. Psychol Aging 2005; 20:272-84

49. Kempen GI, van Heuvelen MJ, van Sonderen E, et al. The relationship of functional limitations to disability and the moderating effects of psychological attributes in community-dwelling older persons. Soc Sci Med 1999;48:1161-72. 